\title{
European multicenter experience with valve-sparing reoperations after the Ross procedure
}

\author{
Aart Mookhoek, MD, ${ }^{\mathrm{a}}$ Laurent de Kerchove, MD, ${ }^{\mathrm{b}}$ Gebrine El Khoury, MD, ${ }^{\mathrm{b}}$ Timo Weimar, MD, ${ }^{\mathrm{c}}$ \\ Giovanni Battista Luciani, MD, ${ }^{d}$ Alessandro Mazzucco, MD, ${ }^{d}$ Ad J. J. C. Bogers, MD, PhD, ${ }^{\text {a }}$ \\ Diana Aicher, MD, ${ }^{\mathrm{e}}$ Hans-Joachim Schäfers, MD, PhD, ${ }^{\mathrm{e}}$ Efstratios I. Charitos, MD, PhD, ${ }^{\mathrm{f}}$ \\ Ulrich Stierle, MD, ${ }^{\mathrm{f}}$ and Johanna J. M. Takkenberg, $\mathrm{MD}, \mathrm{PhD}^{\mathrm{a}}$
}

\begin{abstract}
Background: Autograft valve preservation at reoperation may conserve some of the advantages of the Ross procedure. However, results of long-term follow-up are lacking. In this retrospective multicenter study, we present our experience with valve-sparing reoperations after the Ross procedure, with a focus on long-term outcome.
\end{abstract}

Methods: A total of 86 patients from 6 European centers, who underwent valvesparing reoperation after the Ross procedure between 1997 and 2013, were included in the study.

Results: Reoperation was performed a median of 9.1 years after the Ross procedure in patients with a median age of 38.4 years (interquartile range: 27.1-51.6 years). Preoperative severe autograft regurgitation (grade $\geq 3$ ) was present in $46 \%$ of patients. In-hospital mortality was $1 \%$. During a median follow-up of 4.3 years, 3 more patients died of noncardiac causes, resulting in a cumulative survival at 8 years of $89 \%$ (95\% confidence interval: $65 \%-97 \%)$. Fifteen patients required a reintervention after valve-sparing reoperation, mostly owing to prolapse or retraction of autograft cusps. Freedom from reintervention was 76\% (95\% confidence interval: $57 \%-87 \%$ ) at 8 years. The reintervention hazard was increased in patients who had isolated and/or severe aortic regurgitation at valve-sparing reoperation. In patients without reintervention after valve-sparing autograft reoperation $(n=63)$, severe aortic regurgitation was present in $3 \%$ at last follow-up.

Conclusions: Valve-sparing autograft reoperations after the Ross procedure carry a low operative risk, with acceptable reintervention rates in the first postoperative decade. Patients with isolated and/or severe autograft regurgitation have an increased hazard of reintervention after valve-sparing reoperation; for these patients, careful preoperative weighing of surgical options is required. (J Thorac Cardiovasc Surg 2015;150:1132-7)

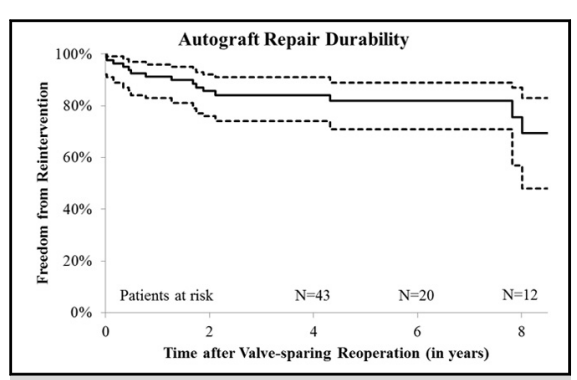

Estimated freedom from reintervention after valvesparing reoperation.

\section{Central Message}

Valve-sparing autograft reoperations carry low operative risk, with acceptable reintervention rates in the first postoperative decade.

\section{Perspective}

This study provides surgeons with important information on the characteristics and outcome after valve-sparing reoperations after the Ross procedure. Durable valve-sparing reoperation is shown to be possible in most patients. However, in patients with isolated autograft regurgitation, careful reconsideration of the surgical approach may be necessary.

See Editorial Commentary page 1138.
Aortic valve replacement through the Ross procedure offers patients a living valve substitute that provides good hemodynamics and freedom from long-term use of anticoagulation methods. The main concern after the Ross procedure in adult patients is reoperation on the autograft, as a result of progressive root dilation and/or autograft insufficiency. ${ }^{1}$

\footnotetext{
From the ${ }^{a}$ Department of Cardio-thoracic Surgery, Erasmus University Medical Center, Rotterdam, The Netherlands; 'bivision of Cardiothoracic and Vascular Surgery, Université Catholique de Louvain, Cliniques Universitaires Saint-Luc, Brussels, Belgium; ' Department of Cardiac Surgery, Sana Cardiac Surgery Stuttgart, Stuttgart, Germany; ${ }^{\mathrm{d} D i v i s i o n}$ of Cardiac Surgery, University of Verona, Verona, Italy; ${ }^{\text {eS}}$ Saarland University Medical Center, Department of Thoracic and Cardiovascular Surgery, Homburg, Germany; and ${ }^{\mathrm{f}}$ Department of Cardiac and Thoracic Vascular Surgery, University of Lübeck, Lübeck, Germany.

This work was supported by the Department of Cardio-thoracic Surgery, Erasmus University Medical Center.
}

Received for publication Jan 19, 2015; revisions received Aug 2, 2015; accepted for publication Aug 12, 2015; available ahead of print Sept 19, 2015.

Address for reprints: Aart Mookhoek, MD, Department of Cardio-thoracic Surgery, Bd577, Erasmus University Medical Center, PO Box 2040, 3000 CA Rotterdam, The Netherlands (E-mail: a.mookhoek@erasmusmc.nl). $0022-5223 / \$ 36.00$

Copyright (C) 2015 by The American Association for Thoracic Surgery http://dx.doi.org/10.1016/j.jtcvs.2015.08.043 
Historically, reoperations after the Ross procedure consisted of excision of autograft material followed by a Bentall procedure. ${ }^{2}$ Currently, surgeons prefer to preserve the autograft valve if possible, by performing a reoperation, to maintain the advantages associated with a functioning valve. ${ }^{3,4}$ However, concern remains about the long-term fate of the autograft cusps after reoperation.

Evidence on outcome after valve-sparing reoperations after the Ross procedure is scarce; only a few centers have published their short-term results. ${ }^{4,5}$ The current retrospective study aims to determine the durability of valve-sparing reoperations after the Ross procedure in the first postoperative decade, in a European multicenter cohort.

\section{METHODS}

Institutional review board permission for this study was obtained in each center. Informed written consent was obtained from all patients. The study was performed in accordance with the Declaration of Helsinki.

\section{Patient Inclusion and Data Collection}

All patients who underwent a valve-sparing reoperation after the Ross procedure in 1 of the 6 participating centers were included in the study. Our cohort includes patients reported on previously by Luciani and colleagues $^{4}(\mathrm{~N}=17)$, de Kerchove and colleagues ${ }^{5}(\mathrm{~N}=26)$, and Charitos and colleagues ${ }^{6}(\mathrm{~N}=24)$.

Preoperative patient characteristics, including information on the initial Ross procedure, perioperative surgical data on the valve-sparing reoperation after the Ross procedure, and postoperative follow-up data were retrospectively collected in each of the participating centers. In all, 86 patients who underwent operation between 1997 and 2013 were included in the study.

\section{Statistical Analysis}

Statistical analyses were performed using IBM SPSS, version 21.0 (IBM, Armonk, NY). Normal distribution of continuous data was assessed using the Shapiro-Wilk test. Continuous variables are displayed as mean $\pm \mathrm{SD}$, or median \pm interquartile range; discrete variables are displayed as counts and percentages.

Overall survival and freedom from reintervention after valve-sparing reoperation were analyzed using the Kaplan-Meier method. Curves were truncated when the number of patients at risk dropped below $9(<10 \%$ of the original population at risk). Ninety-five percent confidence intervals were calculated using log transformation of the cumulative hazard function.

With Cox regression, a univariable analysis of potential risk factors for reintervention after valve-sparing reoperation was performed. Variables included the following: gender; bicuspid aortic valve (yes/no); indication for initial Ross procedure (aortic regurgitation; aortic stenosis; combination); Ross technique (full root; inclusion cylinder; subcoronary); interval from the Ross procedure at time of valve-sparing reoperation; age at time of valve-sparing reoperation; isolated aortic regurgitation as indication for valve-sparing reoperation (yes/no); prolapse (yes/no); severe aortic regurgitation at the time of valve-sparing reoperation (grade $\geq 3$; yes/no); valvesparing autograft root replacement (yes/no); reimplantation versus remodelling technique; annulus repair (yes/no); and isolated autograft valve repair (yes/no). Pearson's correlation coefficient was used to assess correlations between variables included in the univariable analyses. A 1-way ANOVA with Tukey honestly significant difference post hoc test was performed to assess possible differences in reintervention rates after valve-sparing reoperation among the 3 types of valve-sparing autograft root replacement techniques.

\section{RESULTS}

In the participating centers, 1783 Ross procedures were performed from 1997 to 2013. During this period, 87 patients $(44.2 \%)$ received a valve-sparing reoperation after the Ross procedure, of a total of 197 patients who required $\geq 1$ reoperation on the autograft. One patient was excluded from our study population, owing to intraoperative conversion to autograft valve replacement. An overview of patient and procedural characteristics at the time of the initial Ross procedure (Table 1) and of the perioperative details of the valve-sparing reoperation after the Ross procedure (Table 2), as well as details of autograft valve repair (Table 3), are provided. At the time of the valve-sparing reoperation after the Ross procedure, the median age of patients was 38.4 years (interquartile range: 27.1-51.6 years).

\section{Early Outcome}

After the valve-sparing reoperation after the Ross procedure, 1 patient died on day 9 postoperatively after cardiac arrest. With this 1 death, 30-day mortality was $1.2 \%$ (binomial 95\% confidence interval: $0.03 \%-6.24 \%$ ).

One patient, who had isolated autograft valve repair, underwent reintervention after valve-sparing reoperation on day 5 postoperatively, owing to grade III autograft regurgitation. The autograft valve was replaced by a homograft valve. Bleeding complications occurred in 3 patients, requiring resternotomy in 2 . One patient suffered a transient ischemic attack. The median hospital stay was 7 days (interquartile range: 6-9 days; range: 4-17 days).

\section{Late Mortality}

Follow-up after the valve-sparing reoperation after the Ross procedure was $95 \%$ complete, with a median duration of 4.3 years (interquartile range: 2.4-6.3 years; range: 54 days to 16.2 years; 343 patient years). Three cancerrelated deaths occurred at 5.8 years, 7.5 years, and 10.0 years, respectively. Estimated freedom from allcause mortality at 8 years' follow-up was $89 \%$ (95\% confidence interval: $65 \%-97 \%$ ).

\section{Reintervention After Valve-Sparing Reoperation}

Surgical reintervention after valve-sparing reoperation was performed in 15 patients (Table 3). Estimated freedom from reintervention was $76 \%$ at 8 years' follow-up (95\% confidence interval: 57\%-87\%) (Figure 1). Although most autograft cusps appeared thin and pliable at explantation, 2 patients had autograft cusp calcifications.

Univariable analysis revealed several variables that were potentially associated with the hazard of reintervention after valve-sparing reoperation (Table 4). Isolated autograft 
TABLE 1. Patient characteristics at initial Ross procedure

\begin{tabular}{|c|c|}
\hline Characteristic & Value \\
\hline \multicolumn{2}{|l|}{ Gender } \\
\hline Male & $69(80)$ \\
\hline Female & $17(20)$ \\
\hline \multicolumn{2}{|l|}{ Age at Ross procedure (y) } \\
\hline Median & 29.9 \\
\hline Interquartile range & $16.5-42.2$ \\
\hline Range & 7.5-58.3 \\
\hline Children $(<18)$ & $23(27)$ \\
\hline \multicolumn{2}{|l|}{ Native aortic valve } \\
\hline Unicuspid & $6(7)$ \\
\hline Bicuspid & $61(71)$ \\
\hline Tricuspid & $15(17)$ \\
\hline Unspecified & $4(5)$ \\
\hline \multicolumn{2}{|l|}{ Previous cardiac surgery } \\
\hline Patients & $18(21)$ \\
\hline Procedures, $\mathrm{n}$ & 20 \\
\hline \multicolumn{2}{|c|}{ Indication for Ross procedure } \\
\hline Regurgitation & $41(48)$ \\
\hline Stenosis & $16(19)$ \\
\hline Combined & $28(33)$ \\
\hline Unspecified & $1(1)$ \\
\hline \multicolumn{2}{|l|}{ Etiology } \\
\hline Congenital & $49(57)$ \\
\hline Degenerative & $23(27)$ \\
\hline Endocarditis & $4(5)$ \\
\hline Rheumatic & $1(1)$ \\
\hline Prosthesis mismatch & $1(1)$ \\
\hline Prosthesis thrombosis & $1(1)$ \\
\hline Cusp repair failure & $1(1)$ \\
\hline Unspecified & $6(7)$ \\
\hline \multicolumn{2}{|l|}{ Ross technique } \\
\hline Root replacement & $73(85)$ \\
\hline Inclusion cylinder & $10(12)$ \\
\hline Subcoronary & $3(3)$ \\
\hline \multicolumn{2}{|l|}{ RVOT graft type } \\
\hline Homograft & $84(98)$ \\
\hline Bioprosthesis & $2(2)$ \\
\hline
\end{tabular}

Values are $\mathrm{n}(\%)$, unless otherwise indicated. Total patients $=86$. The category of age at Ross procedure does not conform to a normal distribution. RVOT, Right ventricular outflow tract.

valve repair was associated with an increased hazard of reintervention. Estimated freedom from reintervention at 8 years' follow-up was $33 \%$ in patients with isolated autograft valve repair ( 7 of 11), compared with $85 \%$ in patients with valve-sparing autograft root replacement, with or without valve repair ( 8 of 70). Reintervention rates after valve-sparing reoperation were not significantly different for patients who received valve-sparing autograft root replacement using reimplantation (4 of 37), versus remodelling ( 3 of 17), versus the supracoronary technique ( 1 of 16) $(P=.503)$.

Given that the low number of events precluded performing a multivariable analysis, we performed correlation analysis on the variables that were significant in the univariable analysis. Isolated autograft regurgitation as an indication for valve-sparing reoperation after the Ross procedure was negatively correlated with use of the full root technique at the initial Ross procedure (coefficient $-0.459, P<.001)$ and valve-sparing autograft root replacement (coefficient $-0.891, P<.001$ ). It was not correlated with age at the time of valve-sparing reoperation (coefficient $-0.060, P=.594)$.

\section{Clinical Status}

At latest follow-up, $80 \%$ of patients were in New York Heart Association class I, $12 \%$ in class II, and $8 \%$ in class III. Ninety-five percent of patients were in sinus rhythm, $3 \%$ had a permanent pacemaker, and $2 \%$ were diagnosed with atrial fibrillation. Oral anticoagulation was used by $10 \%$ of patients. Several patients experienced cardiacrelated complications during follow-up, including stroke $(8 \%)$, heart failure $(5 \%)$, and myocardial infarction $(2 \%)$. After valve-sparing reoperation after the Ross procedure, at least 4 women had a total of 5 successful pregnancies.

At latest follow-up, 63 patients were still alive and under active follow-up without having had a reintervention after valve-sparing reoperation. Autograft valve regurgitation was absent in $41 \%$ of patients, grade I in $43 \%$, grade II in $13 \%$, and grade III in $3 \%$ of patients.

\section{DISCUSSION}

This multicenter European study provides important information on the characteristics and outcome after valvesparing reoperations after the Ross procedure. The findings illustrate that the indication for surgery, and the presentation of the patient at the time of valve-sparing reoperation, varies widely. Most patients in our cohort underwent the initial Ross procedure as young adults. Therefore, a substantial proportion of patients presented with a bicuspid aortic valve. Somewhat surprisingly, the indication for the Ross procedure was isolated aortic regurgitation in almost one half of the patients. The absence of aortic stenosis as an indication in such a large proportion of patients might be explained in part by prior balloon valvotomy or surgical valvuloplasty in these patients. Another part of the explanation may be that patients in whom the indication for the Ross procedure is aortic stenosis have a lower risk of autograft-related complications.

In experienced hands, valve-sparing reoperation after the Ross procedure is safe, with acceptable early morbidity and mortality. The reported low early mortality is especially striking, considering that in $21 \%$ of patients, the valvesparing reoperation was their third or even fourth cardiac surgical procedure. After the valve-sparing reoperation, patients may again enjoy the claimed benefits of their autograft valve and avoid use of oral anticoagulants. This benefit 
TABLE 2. Characteristics of valve-sparing reoperation after Ross procedure

\begin{tabular}{|c|c|}
\hline Characteristic & Value \\
\hline \multicolumn{2}{|l|}{ Type of procedure } \\
\hline Emergency & $1(1)$ \\
\hline Elective & $79(99)$ \\
\hline \multicolumn{2}{|l|}{ Time after Ross procedure $(\mathrm{y})$} \\
\hline Median & 9.1 \\
\hline Interquartile range & $5.8-12.6$ \\
\hline Range & $0.0-20.7$ \\
\hline \multicolumn{2}{|l|}{ Indication } \\
\hline Aneurysm & $36(42)$ \\
\hline Regurgitation & $16(19)$ \\
\hline Combined & $28(33)$ \\
\hline RVOT graft stenosis & $1(1)$ \\
\hline Unspecified & $5(6)$ \\
\hline \multicolumn{2}{|l|}{ Etiology } \\
\hline Degenerative & $72(84)$ \\
\hline Endocarditis & $6(7)$ \\
\hline Acute dissection & $1(1)$ \\
\hline Unspecified & $7(8)$ \\
\hline \multicolumn{2}{|l|}{ Autograft root diameter, mean (SD; mm)* } \\
\hline Annulus & $26.6 \pm 4.9$ \\
\hline Sinus & $49.7 \pm 5.0$ \\
\hline STJ & $47.0 \pm 5.3$ \\
\hline Ascending aorta & $49.2 \pm 4.9$ \\
\hline \multicolumn{2}{|l|}{ Autograft regurgitation grade $(\mathrm{n}=79)$} \\
\hline None/trace & $3(4)$ \\
\hline I & $17(22)$ \\
\hline II & $23(29)$ \\
\hline III & $23(29)$ \\
\hline IV & $13(16)$ \\
\hline Annulus repair $(\mathrm{n}=80)$ & $57(71)$ \\
\hline Circular annuloplasty $\dagger$ & 40 \\
\hline Cabrol stitches & 16 \\
\hline Unspecified & 1 \\
\hline Valve-sparing autograft root replacement $(\mathrm{n}=81)$ & $70(86)$ \\
\hline Reimplantation & 37 \\
\hline Remodeling & 17 \\
\hline Supracoronary & 16 \\
\hline STJ remodeling $(n=74)$ & $20(27)$ \\
\hline Cusp abnormalities $(\mathrm{n}=81)$ & $33(41)$ \\
\hline Prolapse & 31 \\
\hline Fenestration & 2 \\
\hline Perforation & 3 \\
\hline Retraction & 2 \\
\hline Calcification & 1 \\
\hline Autograft valve repair $(\mathrm{n}=79)$ & $34(43)$ \\
\hline Central plication & 28 \\
\hline Suture-free edge & 10 \\
\hline Pericardial patch & 2 \\
\hline Perfusion time, mean $(\mathrm{SD} ; \mathrm{min} ; \mathrm{n}=66)$ & $145.0 \pm 60.3$ \\
\hline Crossclamp time, mean $(\mathrm{SD} ; \min ; \mathrm{n}=66)$ & $107.1 \pm 46.2$ \\
\hline Circulatory arrest, mean $(\mathrm{SD} ; \min ; \mathrm{n}=54)$ & $4(7)$ \\
\hline & $26.3 \pm 35.0$ \\
\hline
\end{tabular}

TABLE 2. Continued

\begin{tabular}{lc}
\hline \multicolumn{1}{c}{ Characteristic } & Value \\
\hline Concomitant surgery & $20(23)$ \\
RVOT graft replacement & 16 \\
Hemi-arch replacement & 3 \\
ASD closure & 1 \\
VSD closure & 1 \\
\hline
\end{tabular}

Values are $\mathrm{n}$, or $\mathrm{n}(\%)$, unless otherwise indicated. Total number of procedures $\mathrm{N}=86$. For several variables, number of patients from which data were available is indicated by " $(\mathrm{n}=)$ )." The categories of cusp abnormalities, autograft valve repair, and concomitant surgery are overlapping. $R V O T$, Right ventricular outflow tract; $S D$ standard deviation; $S T J$, sinotubular junction; $A S D$, atrial septal defect; $V S D$, ventricular septal defect. *For autograft root diameter, diameters are provided only for patients with autograft root aneurysms, without severe autograft valve regurgitation. $\dagger$ Includes 37 patients who had aortic root reimplantation (David procedure).

is superbly illustrated by the 4 women in our cohort who became pregnant after the valve-sparing reoperation. In our cohort, no cardiac-related deaths were observed during follow-up. This finding suggests that valve-sparing reoperations after the Ross procedure conserve the survival advantage observed after the Ross procedure. ${ }^{7}$ However, the 3 cancer-related deaths resulted in a slightly lower estimated survival at 8 years, compared with the age-matched general population in The Netherlands $(89 \%$ vs $98 \%$; calculated using StatLine; Statistics Netherlands, The Hague, The Netherlands).

Reintervention after valve-sparing reoperation is not uncommon. Most reinterventions were performed within the first 2 postoperative years. This finding may explain why the case reports on valve-sparing reoperations after the Ross procedure do not report failure, as follow-up in these reports rarely extend beyond a few months postoperatively. ${ }^{8,9}$ Most patients who did not require a reintervention were in excellent clinical condition and had good autograft valve function at latest follow-up.

TABLE 3. Reinterventions after valve-sparing reoperation

\begin{tabular}{lc}
\hline \multicolumn{1}{c}{ Reintervention characteristic } & Value \\
\hline Indication & \\
$\quad$ Autograft regurgitation & $13(86.7)$ \\
Autograft stenosis & $1(6.7)$ \\
Autograft root dilation & $1(6.7)$ \\
Cusp abnormalities & \\
$\quad$ Prolapse & $8(66.7)$ \\
Retraction & $4(26.7)$ \\
Combination & $1(6.7)$ \\
Calcifications & $2(13.3)$ \\
Procedure & \\
Autograft valve repair & $1(6.7)$ \\
Replacement with mechanical prosthesis & $10(53.3)$ \\
Replacement with biological prosthesis & $4(26.7)$ \\
\hline Values are $\mathrm{n}(\%)$. Total $\mathrm{N}=15$. &
\end{tabular}



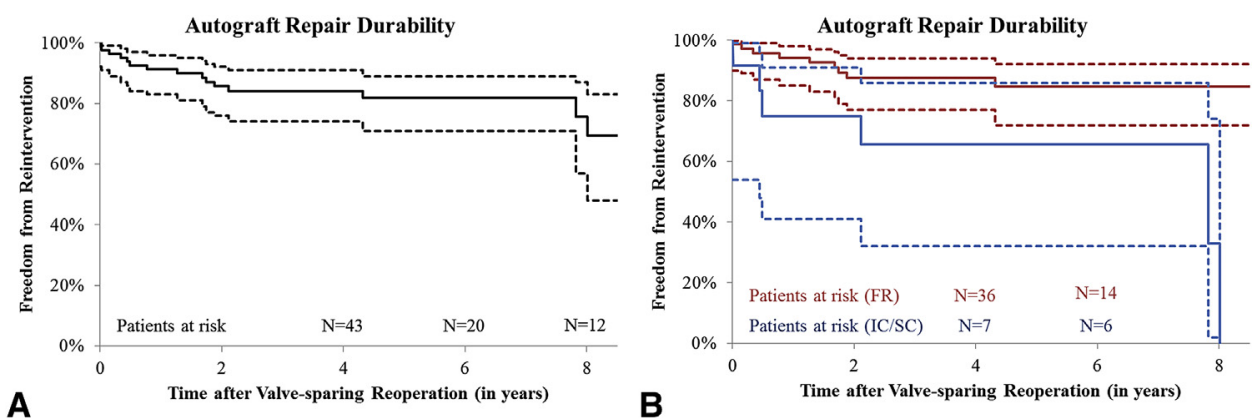

FIGURE 1. Kaplan-Meier curve of freedom from reintervention after valve-sparing reoperation: (A) entire cohort and (B) cohort split according to operation technique used at the time of the Ross procedure. Techniques are indicated in parentheses. FR, Full root; $I C$, inclusion cylinder; $S C$, subcoronary.

We have identified several factors related to characteristics of the patient and to the initial Ross procedure, as well as to autograft valve function at the time of the valvesparing reoperation, that are associated with reintervention. These findings may help guide the decision-making process when reoperation on the pulmonary autograft is needed.

The technique used for the initial Ross procedure was associated with outcome after the valve-sparing reoperation. Compared with the full root technique, the inclusion cylinder technique was associated with an increased risk of failure of the valve-sparing reoperation. Although a similar association in the subcoronary group was not statistically significant, this lack of significance may be attributed to the limited number of patients in this group.

We believe that the inclusion cylinder and subcoronary techniques may lead to distortion of the complex geometry of the autograft cusps. Over time, this may lead to cusp prolapse and other degenerative cusp changes in some patients. Not surprisingly, most patients in whom the initial Ross procedure was performed according to the inclusion cylinder or subcoronary technique presented with isolated, and often severe, autograft regurgitation at the time of reoperation.

TABLE 4. Univariable analysis of the hazard of reintervention after valve-sparing reoperation

\begin{tabular}{lcc}
\hline \multicolumn{1}{c}{ Variable } & Hazard ratio $(\mathbf{9 5} \% \mathbf{C I})$ & $\boldsymbol{P}$ value \\
\hline Ross technique & 1.000 & \\
$\quad$ Full root & $4.358(1.454-13.064)$ & .009 \\
$\quad$ Inclusion cylinder & $4.005(0.497-32.286)$ & .193 \\
$\quad$ Subcoronary & $0.944(0.906-0.985)$ & .007 \\
Age & $5.021(1.721-14.649)$ & .003 \\
Isolated aortic regurgitation & & \\
$\quad$ (as repair indication) & $3.736(1.165-11.978)$ & .027 \\
$\begin{array}{l}\text { Severe aortic regurgitation } \\
\quad \text { grade } \geq 3) *\end{array}$ & \\
$\begin{array}{l}\text { Isolated autograft valve repair } \\
\text { Valve-sparing autograft root }\end{array}$ & $5.041(1.677-15.154)$ & .004 \\
$\quad$ replacement & $0.199(0.070-0.565)$ & .002 \\
CI, Confidence interval. *At the time of valve-sparing reoperation after Ross \\
procedure.
\end{tabular}

Prolapse and degenerative cusp changes present at the time of reoperation may prevent reoperation durability. In addition, such reoperations may be technically more challenging with use of the inclusion cylinder or subcoronary technique, owing to scarring and possible reduced compliance of the autograft wall. A substantial proportion of these patients who required a reintervention after the valvesparing reoperation presented with prolapse and/or retraction of $\geq 1$ cusps at the time of reintervention. The 2 patients in whom cusp calcifications were reported at the time of autograft valve explantation had an inclusion cylinder Ross procedure.

In contrast, use of the full root technique at the initial Ross procedure preserves the complex geometry of the autograft root. After the full root technique, the predominant mechanism of failure is autograft root dilation, generally with either only moderate autograft regurgitation, or none. Degenerative cusp changes are expected to be limited. Supporting this theory is our finding that in patients in whom the full root technique was used, autograft root aneurysm was the indication for a valve-sparing autograft root replacement in most patients. The interval between the initial Ross procedure and the valve-sparing reoperation was longer when the indication for reoperation was autograft root aneurysm (10.7 years), compared with isolated autograft regurgitation (3.4 years).

Our findings are in accordance with 2 smaller cohort studies that showed an association between isolated autograft valve pathology and reintervention after valvesparing reoperation. ${ }^{4,5}$ In a case series with 7 patients, the authors did not report any reintervention after a mean echocardiographic follow-up of 3.2 years. ${ }^{10}$ Their excellent results may be explained in part by the absence of patients who had isolated autograft regurgitation. Reported results after primary valve-sparing aortic root operations are excellent: de Kerchove and colleagues ${ }^{11}$ report a freedom from reoperation after primary valve-sparing aortic root operation at 8 years of $90 \%$; Aicher and colleagues ${ }^{12}$ report $96 \%$ at 10 years. These results are comparable to our reported freedom from reintervention of $85 \%$ at 8 years in 
the subgroup of patients who received valve-sparing autograft root replacement.

Durable valve-sparing reoperations after the Ross procedure in patients with diseased autograft cusps may not be possible in some patients, especially when isolated autograft regurgitation is present, or may require careful consideration of the surgical approach. Several participating centers do not consider patients with leaflet calcifications, fenestrations, or retraction-suitable candidates for valvesparing reoperations after the Ross procedure. Given this context, some centers advocate the use of intraoperative measurements of the autograft cusps to guide the reoperation. Although this approach may prove to be more reliable than visual inspection with the naked eye, no difference in outcome of autograft valve repair was observed in the current study between centers that used intraoperative measurements versus those that did not. In patients in whom a durable repair is unlikely, surgeons may consider the Bentall procedure with implantation of a mechanical or biological prosthesis.

\section{Limitations}

The retrospective nature of this study resulted in limitations with respect to data collection, because information on several variables was not available for all patients. These limitations underscore the need for a prospective registry to assess (variables associated with) outcome of valve-sparing reoperations after the Ross procedure. Such a registry may have been achieved in the recently initiated AVIATOR (http://heartvalvesociety.org/working-groups.cgi), a prospective international registry of patients undergoing surgery for ascending aorta aneurysm and/or isolated aortic regurgitation.

\section{CONCLUSIONS}

Valve-sparing reoperations after the Ross procedure may be performed with limited early morbidity and mortality in most patients. This approach provides patients with the continued benefit of a functioning autograft valve. However, the need for reintervention after valve-sparing reoperation is common in the first 2 postoperative years in patients with isolated and/or severe autograft regurgitation; careful consideration of the surgical approach in these patients is warranted.

\section{Conflict of Interest Statement}

Dr Weimar reports consulting fees from Atricure. All other authors have nothing to disclose with regard to commercial support.

The authors thank Corinne Coulon (Division of Cardiothoracic and Vascular Surgery, Université Catholique de Louvain, Cliniques Universitaires Saint-Luc, Brussels, Belgium) for her help with data collection.

\section{References}

1. Stelzer P. The Ross procedure: state of the art 2011. Semin Thorac Cardiovasc Surg. 2011;23:115-23.

2. Elkins RC, Lane MM, McCue C. Pulmonary autograft reoperation: incidence and management. Ann Thorac Surg. 1996;62:450-5.

3. David TE. Aortic valve sparing operations: a review. Korean J Thorac Cardiovasc Surg. 2012;45:205-12

4. Luciani GB, Lucchese G, De Rita F, Puppini G, Faggian G, Mazzucco A. Reparative surgery of the pulmonary autograft: experience with Ross reoperations. Eur J Cardiothorac Surg. 2012;41:1309-14; discussion 1314-5.

5. de Kerchove L, Boodhwani M, Etienne PY, Poncelet A, Glineur D, Noirhomme P, et al. Preservation of the pulmonary autograft after failure of the Ross procedure. Eur J Cardiothorac Surg. 2010;38:326-32.

6. Charitos EI, Takkenberg JJ, Hanke T, Gorski A, Botha C, Franke U, et al. Reoperations on the pulmonary autograft and pulmonary homograft after the Ross procedure: an update on the German Dutch Ross Registry. J Thorac Cardiovasc Surg. 2012;144:813-21; discussion 821-3.

7. El-Hamamsy I, Eryigit Z, Stevens LM, Sarang Z, George R, Clark L, et al. Longterm outcomes after autograft versus homograft aortic root replacement in adults with aortic valve disease: a randomised controlled trial. Lancet. 2010;376 524-31.

8. Watanabe N, Saito S, Saito H, Kurosawa H. Valve-sparing aortic root replacement with repair of leaflet prolapse after Ross operation. Interact Cardiovasc Thorac Surg. 2007;6:89-91.

9. Goldstone AB, Woo YJ. Pulmonary autograft leaflet repair and valve sparing root replacement to correct late failure of the Ross procedure. J Card Surg. 2013;28: 496-9.

10. Brinkman WT, Herbert MA, Prince SL, Ryan C, Ryan WH. Redo autograf operations after the Ross procedure. Ann Thorac Surg. 2012;93:1477-81; discussion 1481-2.

11. de Kerchove L, Boodhwani M, Glineur D, Poncelet A, Verhelst R, Astarci P, et al Effects of preoperative aortic insufficiency on outcome after aortic valve-sparing surgery. Circulation. 2009;120(11 Suppl):S120-6.

12. Aicher D, Langer F, Lausberg H, Bierbach B, Schäfers HJ. Aortic root remodeling: ten-year experience with 274 patients. J Thorac Cardiovasc Surg. 2007;134 909-15.

Key Words: Ross procedure, reoperation, valve-sparing, follow-up 